\title{
Memprediksi Penghasilan Bulan Berikutnya Menggunakan Logika Fuzzy Tsukamoto Pada Ternak Ayam Potong (Bloiler) Buntu Atas
}

\author{
Muhammad Aliyul Amri' ${ }^{1}$, Apriyadi², Syafitri Warda Ningsih ${ }^{3}$, Anju Vlaudya Sinaga ${ }^{4}$, Surmaya \\ Santi ${ }^{5}$ \\ STIKOM Tunas Bangsa, Pematangsiantar, Indonesia ${ }^{1}$ \\ Jl. Jendral Sudirman Blok A No. 1/2/3 \\ muhammadaliyul.amri12@gmail.com ${ }^{1}$, apriyadi2301997@gmail.com², \\ syafitriwarda99@gmail.com ${ }^{3}$, anjuvlaudya2000@gmail.com ${ }^{4}$, santi.surmaya045@gmail.com ${ }^{5}$
}

\begin{abstract}
Chicken livestock is an animal farm that is growing in the district. Panei of North Sumatra. Cut chicken is the most common in livestock by the community, because the demand for the production of broiler chicken is always increasing rapidly every month. Most breeders have difficulty calculating income in the following month, because the following month's income can support the productivity of future chicken. In order to overcome this problem, artificial intelligence systems such as Fuzzy Tsukamoto are needed. This fuzzy Tsukamoto method was chosen because each consequence of the rules in the form of IF-THEN is represented by using a fuzzy set of monotonous membership functions and can help farmers to calculate their maximum income every month. The results of the Tsukamoto fuzzy method are in the form of a calculation that generates the following month's income on the Buntu Above Breeds that are prioritized in order to help farmers advance their business.
\end{abstract}

Keywords: Fuzzy Tsukamoto, broiler chicken, income

\begin{abstract}
Abstrak- Ternak ayam merupakan sebuah peternakan hewani yang sangan berkembang didaerah Kec. Panei Sumatera Utara. Ayam Potong merupakan yang paling umum di ternak oleh masyarakat, karena permintaan produksi ayam potong yang selalu meningkat pesat setiap bulannya. Kebanyakan peternak kesulitan untuk menghitung penghasilan di bulan berikutnya, karena penghasilan bulan berikutnya dapat menunjang produktifitas ayam potong kedepannya. Untuk dapat mengatasi permasalahan ini, diperlukan system kecerdasan buatan seperti Fuzzy tsukamoto. Metode fuzzy Tsukamoto ini dipilih karena setiap konsekuen pada aturan yang berbentuk IF- THEN direpresentasikan dengan menggunakan himpunan fuzzy pada fungsi keanggotaan yang monoton dan dapat membantu peternak dalam menghitung penghasilan terbaknya setiap bulan. Hasil dari metode fuzzy tsukamoto ini berupa perhitungan yang menghasilkan penghasilan bulan berikutnya pada Ternak Ayam Potong(Bloiler) Buntu Atas yang diproritaskan agar dapat membantu peternak memajukan usahanya.
\end{abstract}

Kata kunci: Fuzzy Tsukamoto, ayam potong, penghasilan

\section{PENDAHULUAN}

Perkembangan dunia bisnis baik bisnis ternak ayam potong (broiler) pada sekarang ini sangatlah cepat, serta kebutuhan konsumen akan ayam potong semangkin meningkat. Penghasilan pendapatan ternak ayam potong perlu diprediksi dengan akurat, karena hasil prediksi yang akurat sangat penting untuk dapat diambil keputusanyang tepat agar dapat diketahui bagaimana potensi ternak ayam potong yang benar-benar dapat menguntungkan. Penelitian ini Membahas Tentang Metode Fuzzy Tsukamoto yang merupakan metode yang digunakan dalam pengambilan keputusan seperti halnya menentukan penghasilan suatu instansi. Fuzzy logic pertama sekali di temukan pada pertengahan 1960, oleh Prof. Lotfi Zadeh dari universitas California di Barkeley menemukan bahwa hukum benar 
atau salah dari logika boolean tidak memperhitungkan beragam kondisi yang nyata[1]. Metode fuzzy Tsukamoto ini dipilih karena setiap konsekuen pada aturan yang berbentuk IF- THEN direpresentasikan dengan menggunakan himpunan fuzzy pada fungsi keanggotaan yang monoton[2].

Logika Fuzzy nilai keanggotaan berada diantara 0 dan 1. Artinya, bisa saja suatu keadaan mempunyai dua nilai "Ya dan Tidak", "Benar dan Salah", "Baik dan Buruk" secara bersamaan, namun besar nilainya tergantung pada bobot keanggotaan yang dimilikinya[3]. Berdasarkan uraian diatas, metode tsukamoto dirasa saat cocok dalam penyelesaian permasalahan penentuan penghasilan ternak ayam potong di bulan berikutnya. Penelitian ini bertujuan untuk menghasilkan sebuah sistem pendukung keputusan yang dapat membantu peternak dalam menentukan penghasilan ternak ayam

\section{METODOLOGI PENELITIAN}

Penelitian ini dilakukan dengan menggunakan data jumlah penghasilan setiap bulannya di di Ternak Ayam Potong (Bloiler) Buntu Atas tahun 2019. Data yang diperoleh dari Ternak Ayam Potong (Bloiler) Buntu Atas terdiri dari 5 variabel yaitu ayam masuk, biaya oprasional, pakan, hasil ayam dan penghasilan.

\subsection{Fungsi Keanggotaan Logika Fuzzy}

Fungsi keanggotaan yang digunakan dalam perencanaan adalah fungsi keanggotaan linier [4]. Fungsi keanggotaan ini dipilih karena merupakan suatu model yang terstruktur dan sistematis, dimana pekerjaan untuk setiap tahapan harus selesai dilakukan agar bias berlanjut ke tahap berikutnya[5]. Berikut ini contoh kurva fungsi keanggotaan linier :

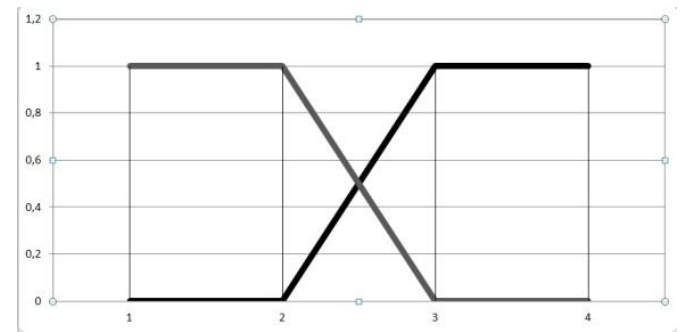

Gambar 1. Kurva Fungsi Keanggotaan Linier

\subsection{Perancangan Logika Fuzzy}

Dalam merancang Fuzzy Tsukamoto yang digunakan untuk memprediksi penghasilan bulan berikutnya pada Ternak Ayam Potong (Bloiler) Buntu Atas meliputi kriteria, fuzzifikasi dan pembentukan rule[2].

a. Kriteria

Kriteria yang digunakan dalam prediksi penghasilan ternak ayam menggunakan Fuzzy Tsukamoto pada Ternak Ayam Potong (Bloiler) Buntu Atas yaitu :

1. Ayam masuk

2. Biaya oprasional

3. Pakan 
4. Hasil ayam

5. Penghasilan

b. Fuzzifikasi

Berdasarkan kriteria yang digunakan ada 5 variable yang dapat dimodelkan yaitu ayam masuk, biaya oprasional, pakan, hasil ayam dan penghasilan.

1. Kriteria Ayam Masuk

Dari hasil wawancara oleh pihak Ternak Ayam Potong (Bloiler) Buntu Atas dikatakan sedikit jika $<=6000$ dan banyak jika $>=6500$. Kriteria ayam masuk dibagi menjadi 2 himpunan fuzzy, yaitu SEDIKIT[6000], BANYAK[6500].

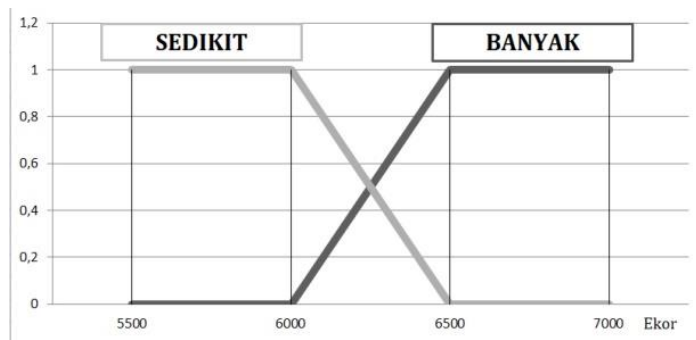

Gambar 2. Fungsi Keanggotaan Pada Kriteria Ayam Masuk

Fungsi keanggotaan pada kriteria ayam masuk dirumuskan sebagai berikut :

$$
\text { Ayam masukSEDIKIT } \begin{cases}1 & x_{\perp}<=6000 \\ \frac{6500-x_{l}}{500} & 6000<x_{l}<6500 \\ 0 & x_{l}>=6500\end{cases}
$$

Gambar 3. Rumus Fungsi Keangotaan Pada Kriteria Ayam Masuk Sedikit

$$
\text { Ayam masukBANYAK }^{[x]} \begin{cases}1 & x_{1}>=6500 \\ \frac{x_{l}-6000}{500} & 6000<x_{1}<6500 \\ 0 & x_{1}<=6000\end{cases}
$$

Gambar 4. Rumus Fungsi Keangotaan Pada Kriteria Ayam Masuk Banyak

2. Kriteria Biaya Oprasional

Dari hasil wawancara oleh pihak Ternak Ayam Potong (Bloiler) Buntu Atas dikatakan sedikit jika $<=1500000$ dan banyak jika $>=2000000$. Kriteria ayam masuk dibagi menjadi 2 himpunan fuzzy, yaitu SEDIKIT[1500000], BANYAK[2000000]. 


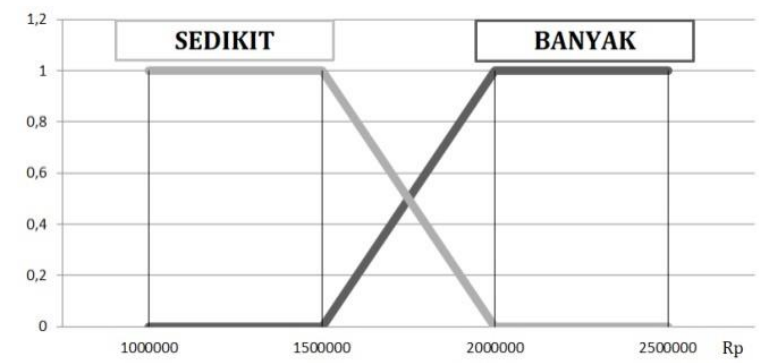

Gambar 5. Fungsi Keangotaan Pada Kriteria Biaya Oprasional

Fungsi keanggotaan pada kriteria biaya oprasional dirumuskan sebagai berikut :

$$
\text { Biaya OprasionalSEDIKIT } \left.{ }^{[x]}\right] \begin{cases}1 & x_{2}<=1500000 \\ \frac{2000000-x_{2}}{500000} & 1500000<x_{2}<2000000 \\ 0 & x_{2}>=2000000\end{cases}
$$

Gambar 6. Rumus Fungsi Keangotaan Pada Kriteria Biaya Oprasional Sedikit

$$
\text { Biaya OprasionalBANYAK }{ }^{[x]} \begin{cases}1 & x_{2}>=2000000 \\ \frac{x_{2}-1500000}{500000} & 1500000<x_{2}<2000000 \\ 0 & x_{2}<=1500000\end{cases}
$$

Gambar 7. Rumus Fungsi Keangotaan Pada Kriteria Biaya Oprasional Banyak

3. Kriteria Pakan

Dari hasil wawancara oleh pihak Ternak Ayam Potong (Bloiler) Buntu Atas dikatakan sedikit jika $<=170000000$ dan banyak jika $>=180000000$. Kriteria ayam masuk dibagi menjadi 2 himpunan fuzzy, yaitu SEDIKIT[170000000], BANYAK[180000000].

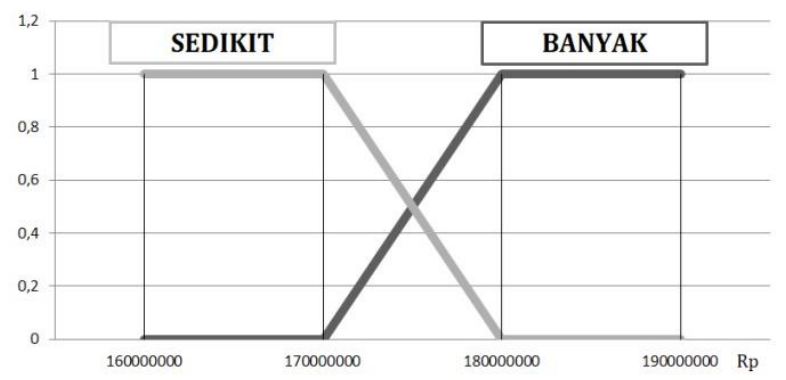

Gambar 8. Fungsi Keanggotaan Pada Kriteria Pakan

Fungsi keanggotaan pada kriteria pakan dirumuskan sebagi berikut : 


$$
\text { PakanSEDIKIT }{ }^{\left[x_{3}\right]} \begin{cases}1 & \underline{x_{3}}<=170000000 \\ \frac{180000000-x_{3}}{10000000} & 170000000<x_{3}<180000000 \\ 0 & x_{3}>=180000000\end{cases}
$$

Gambar 9. Rumus Fungsi Keangotaan Pada Kriteria Pakan Sedikit

$$
\text { PakanBANYAK }^{\left[x_{3}\right]} \begin{cases}1 & x_{3}>=180000000 \\ \frac{x_{3}-170000000}{10000000} & 170000000<x_{3}<180000000 \\ 0 & x_{3}<=170000000\end{cases}
$$

Gambar 10. Rumus Fungsi Keangotaan Pada Kriteria Pakan Banyak

4. Kriteria Hasil Ayam

Dari hasil wawancara oleh pihak Ternak Ayam Potong (Bloiler) Buntu Atas dikatakan turun jika $<=10800$ dan naik jika $>=12000$. Kriteria ayam masuk dibagi menjadi 2 himpunan fuzzy, yaitu TURUN[10800], NAIK[12000].

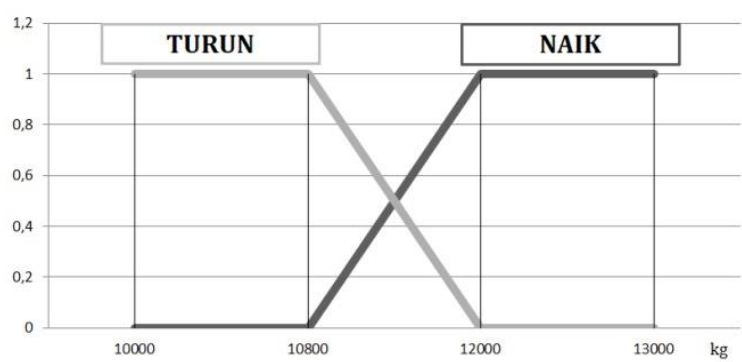

Gambar 11. Fungsi Keanggotaan Pada Kriteria Hasil Ayam

Fungsi keanggotaan pada kriteria hasil ayam dirumuskan sebagi berikut :

$$
\text { Hasil AyamTURUN }^{[x]} \begin{cases}1 & x_{4}<=10800 \\ \frac{12000-x_{4}}{1200} & 10800<x_{4}<12000 \\ 0 & x_{4}>=12000\end{cases}
$$

Gambar 12. Rumus Fungsi Keangotaan Pada Kriteria Hasil Ayam Turun

$$
\text { Hasil AyamTURUN }^{[x]} \begin{cases}1 & x_{4}>=12000 \\ \frac{x_{4}-10800}{1200} & 10800<x_{4}<12000 \\ 0 & \underline{x}_{4}<=10800\end{cases}
$$

Gambar 13. Rumus Fungsi Keangotaan Pada Kriteria Hasil Ayam Naik 
5. Kriteria Penghasilan

Dari hasil wawancara oleh pihak Ternak Ayam Potong (Bloiler) Buntu Atas dikatakan berkurang jika <=194000000 dan bertambah jika >=216000000. Kriteria ayam masuk dibagi menjadi 2 himpunan fuzzy, yaitu BERKURANG[194000000], BERTAMBAH[216000000].

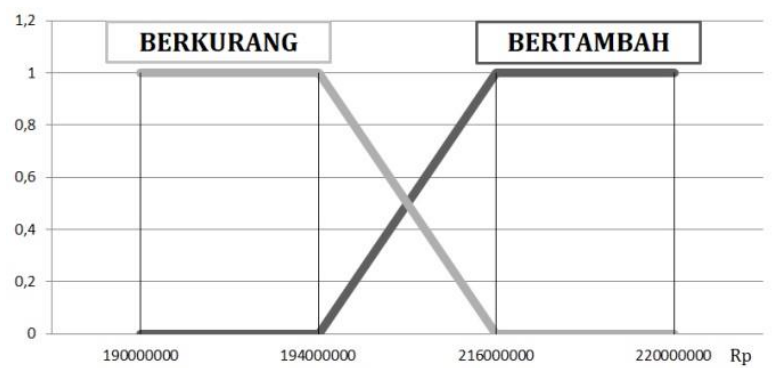

Gambar 14. Fungsi Keanggutaan Pada Kriteria Penghasilan

Fungsi keanggotaan pada kriteria penghasilan dirumuskan sebagi berikut :

$$
\text { PenghasilanBERKURANG }{ }^{[x]} \begin{cases}1 & x_{5}<=194000000 \\ \frac{216000000-x_{5}}{22000000} & 194000000<x_{5}<216000000 \\ 0 & x_{5}>=216000000\end{cases}
$$

Gambar 15. Rumus Fungsi Keangotaan Pada Kriteria Penghasilan Berkurang

$$
\text { PenghasilanBERTAMBAH }^{\left[x^{5}\right]} \begin{cases}1 & x_{5}>=216000000 \\ \frac{x_{5}-194000000}{22000000} & 194000000<x_{5}<216000000 \\ 0 & x_{5}<=194000000\end{cases}
$$

Gambar 16. Rumus Fungsi Keangotaan Pada Kriteria Penghasilan Bertambah

c. Pembentukan Rule

Hasil Rule dalam memprediksi penghasilan bulan berikutnya menggunakan Fuzzy Tsukamoto pada Ternak Ayam Potong (Bloiler) Buntu Atas seperti pada table

Tabel 1. Rule

\begin{tabular}{|l|l|l|l|l|l|}
\hline \multirow{2}{*}{ RULE } & \multicolumn{4}{|l|}{ IF } & THEN \\
\cline { 2 - 6 } & Ayam Masuk & Biaya Operasional & Pakan & Hasil Ayam & Penghasilan \\
\hline R1 & Sedikit & Sedikit & Sedikit & Sedikit & Berkurang \\
\hline R2 & Sedikit & Sedikit & Sedikit & Banyak & Berkurang \\
\hline R3 & Sedikit & Sedikit & Banyak & Sedikit & Berkurang \\
\hline R4 & Sedikit & Sedikit & Banyak & Banyak & Bertambah \\
\hline R5 & Sedikit & Banyak & Sedikit & Sedikit & Berkurang \\
\hline R6 & Sedikit & Banyak & Sedikit & Banyak & Bertambah \\
\hline
\end{tabular}

Penghasilan Bulan Berikutnya Ternak Ayam Potong(Muhammad Aliyul Amri) | 899 


\begin{tabular}{|c|c|c|c|c|c|}
\hline \multirow[t]{2}{*}{ RULE } & \multicolumn{4}{|l|}{ IF } & \multirow{2}{*}{$\begin{array}{l}\text { THEN } \\
\text { Penghasilan }\end{array}$} \\
\hline & Ayam Masuk & Biaya Operasional & Pakan & Hasil Ayam & \\
\hline R7 & Sedikit & Banyak & Banyak & Sedikit & Bertambah \\
\hline R8 & Sedikit & Banyak & Banyak & Banyak & Bertambah \\
\hline R9 & Banyak & Sedikit & Sedikit & Sedikit & Berkurang \\
\hline R10 & Banyak & Sedikit & Sedikit & Banyak & Berkurang \\
\hline R11 & Banyak & Sedikit & Banyak & Sedikit & Berkurang \\
\hline R12 & Banyak & Sedikit & Banyak & Banyak & Bertambah \\
\hline R13 & Banyak & Banyak & Sedikit & Sedikit & Berkurang \\
\hline R14 & Banyak & Banyak & Sedikit & Banyak & Bertambah \\
\hline R15 & Banyak & Banyak & Banyak & Sedikit & Bertambah \\
\hline R16 & Banyak & Banyak & Banyak & Banyak & Bertambah \\
\hline
\end{tabular}

\section{HASIL DAN PEMBAHASAN}

Proses Fuzzifikasi dilakukan dengan merubah nilai input $\left(x_{n}\right)$ kedalam bentuk derajat keanggotaan masing-masing kriteria. Sebelum dilakukan perhitungan Fuzzifikasi, setiap kriteria haruslah memiliki satu nilai yang merepresentasikan kriteria tersebut[6]. Maka dari hasil wawancara oleh pihak Ternak Ayam Potong (Bloiler) Buntu Atas diketahui pada bulan berikutnya ayam masuk = 6200 ekor, biaya oprasional $=1600000$, pakan $=178000000$, hasil ayam $=1100 \mathrm{~kg}$ dan Penghasilan belum diketahui.

\subsection{Perhitungan Fuzzifikasi}

Dari perumusan fungsi keanggotaan pada setiap kriteria fuzzifikasi, maka dapat diketahui nilai keanggotaan pada setiap kriteria fuzzifikasi.

$$
\begin{aligned}
\text { Ayam Masuk SEDIKIT } & {[x 1]=\frac{6500-x}{500} } \\
& =\frac{6500-6200}{500} \\
& =0,6
\end{aligned}
$$

Ayam Masuk BANYAK ${ }^{[x 1]}=\frac{x-6000}{500}$

$$
\begin{aligned}
& =\frac{6200-6000}{500} \\
& =0,4
\end{aligned}
$$

\subsection{Perhitungan Rule}

Dari perhitungan fuzzifikasi , maka dapat diketahui nilai rule pada setiap rule yang disediakan, untuk rule pertama yaitu :

R1=Min ( Ayam Masuk[Sedikit] ; Biaya Oprasional[Sedikit] ; Pakan[Sedikit] ; Hasil Ayam[Turun])

$\mathrm{R} 1=\operatorname{Min}(0,6 ; 0,8 ; 0,2 ; 0,83333)$

$\mathrm{R} 1=0,2$

Maka dapat diketahui nilai keanggotaan pada kriteria penghasilan pada rule pertama $=0,2$, dan dapat diketahui nilai $x^{5}$ pada rule pertama(C1)

Penghasilan BERKURANG ${ }^{[x 5]}=\frac{216000000-x_{5}}{22000000}$ 


$$
\begin{aligned}
0,2 & =\frac{216000000-x_{5}}{22000000} \\
4400000 & =22000000-x_{5} \\
x_{5} & =211600000
\end{aligned}
$$

\subsection{Perhitungan Akhir}

Dari perhitungan rule dan diketahui nilai keanggotaan pada kriteria penghasilan dari setiap rule, maka dapat diketahui perhitungan akhir dari karya ilmia ini

$$
\begin{aligned}
\text { Penghasilan } & =\frac{(C 1 \times R 1)+(C 2 \times R 2)++\cdots+(C 16 \times R 16)}{R 1+R 2+\cdots+R 16} \\
& =\frac{(2116000 \times 0,2)+(212333333,3333 \times 0,1667)++\ldots+(197666666,6667 \times 0,167)}{0.2+0,1667+\cdots+0,167} \\
& =\frac{721644444,4444}{3.5333} \\
& =204238993,7 \\
& =R p .204 .238 .994,-
\end{aligned}
$$

\section{KESIMPULAN}

Hasil prediksi penghasilan bulan berikutnya menggunakan logika fuzzy tsukamoto pada Ternak Ayam Potong (Bloiler) Buntu Atas memperlihatkan nilai akhir pada penghasilan bulan berikutnya sebesar $\mathrm{Rp}$ 204.238.994,--. Hasil pergitungan prediksi ini hanya untuk mendukung keputusan pada prediksi jumlah penghasilan pada bulan berikutnya, bukan untuk system pendukung keputusan. Oleh sebab itu untuk penghasilan bulan berikutnya tetap tergantung pada peternak dan masalah yang dihadapi dan tidak harus menggunakan perhitungan yang ditampilkan.

\section{DAFTAR PUSTAKA}

[1] N. Novita, "Metode Fuzzy Tsukamoto Untuk Menentukan Beasiswa," Jurnal \& Penelitian Teknik Informatika, vol. 1, no. 1, pp. 51-54, 2016.

[2] T. Ulul Azmi, H. Haryanto, and T. Sutojo, "Prediksi Jumlah Produksi Jenang di PT Menara Jenang Kudus Menggunakan Metode Logika Fuzzy Tsukamoto," Jurnal Ilmiah SISFOTENNIKA, vol. 8, no. 1, pp. 23-34, 2018.

[3] I. N. Farida and A. B. Setiawan, "Perbandingan Metode Fuzzy Tsukamoto dan Sugeno Dalam Memprediksi Keuntugan," Simki-Techsain, vol. 1, no. 4, pp. 1-11, 2017.

[4] A. Wanto, "Analisis Penerapan Fuzzy Inference System (FIS) Dengan Metode Mamdani Pada Sistem Prediksi Mahasiswa Non Aktif (Studi Kasus : AMIK Tunas Bangsa Pematangsiantar)," in Seminar Nasional Inovasi Dan Teknologi Informasi (SNITI) 3, 2016, vol. 3, pp. 393-400.

[5] H. R. AH, "Fuzzy Inference System Dengan Metode Tsukamoto Sebagai Penunjang Keputusan Produksi ( Studi Kasus : PT . Talkindo Selaksa Anugrah )," Jurnal Sistem Informasi (JSI), vol. 7, no. April, pp. 753-764, 2015.

[6] M. Yusida, D. Kartini, A. Farmadi, R. Adi Nugroho, and Muliyadi, "IMPLEMENTASI FUZZY TSUKAMOTO DALAM PENENTUAN KESESUIAN LAHAN UNTUK TANAMAN KATER DAN KELAPA SAWIT," Kumpulan Jurnal Ilmu Komputer (KLIK)2, vol. 4, no. 2, pp. 233-246, 2017. 